\title{
Lexicography and Sign Language Engineering: The Zambian Experience
}

\author{
Vincent M. Chanda, Department of Literature and Languages, \\ University of Zambia, Zambia
}

\begin{abstract}
Sign language as used by deaf communities, is a real and fully-fledged human language, not based on any spoken language, and not universal in the sense of there being only one sign language worldwide. A deaf community is a linguistic minority, but a linguistic minority with special linguistic needs because of the very nature of sign language. In Zambia, like in the vast majority of other Third World countries, the linguistic needs of deaf and hard-of-hearing people have been ignored. This article examines the genesis and implementation of a dictionary project for sign language, the Zambian Sign Language Dictionary Project, regarded as a first step towards the development of a Zambian National Sign Language. The article highlights the specificity of sign language lexicography.
\end{abstract}

Keywords: AMERICAN SIGN LANGUAGE, ARTICULATED LANGUAGE, BORROWING, DEAF, HAND SHAPE, HARD-OF-HEARING, ICONICITY, INDIGENOUS SIGN, LOCATION, MOVEMENT, ORIENTATION, SIGN, SIGN LANGUAGE, SIGN-WORD SEARCH SYSTEM, WORD-SIGN SEARCH SYSTEM

Opsomming: Leksikografie en gebaretaalontwikkeling: Die Zambiese ervaring. Gebaretaal, soos deur dowe gemeenskappe gebruik, is ' $n$ ware en volwaardige menslike taal wat nie op enige gesproke taal gebaseer is nie, en nie universeel is in die sin dat daar slegs een gebaretaal ter wêreld is nie. ' $n$ Dowe gemeenskap is ' $n$ taalkundige minderheid, maar 'n minderheid met spesiale taalbehoeftes juis weens die besondere aard van gebaretaal. In Zambië, soos in die oorgrote meerderheid van ander Derdewêreldlande, is die taalkundige behoeftes van dowe en hardhorende persone geïgnoreer. Hierdie artikel ondersoek die ontstaan en verwesenliking van 'n woordeboekprojek vir gebaretaal, die Woordeboekprojek vir Zambiese Gebaretaal, wat beskou word as die eerste stap na die ontwikkeling van 'n Zambiese Nasionale Gebaretaal. Die artikel beklemtoon die spesifiekheid van gebaretaalleksikografie.

Sleutelwoorde: AMERIKAANSE GEBARETAAL, GESPROKE TAAL, ONTLENING, DOOF, HANDVORM, HARDHOREND, IKONISITEIT, INHEEMSE GEBAAR, POSISE, BEWEGING, ORIENTASIE, GEBAAR, GEBARETAAL, GEBAAR-WOORD-SOEKSISTEEM, WOORDGEBAAR-SOEKSISTEEM

\section{Introduction}

The present article examines the genesis and implementation of a sign lanLexikos 7 (AFRILEX-reeks/series 7: 1997): 192-206 
guage lexicographic project, the Zambian Sign Language Dictionary Project, a project of the Zambian National Association of the Deaf (ZNAD). The editorial work was supervised by the writer and the product, i.e. the dictionary, is currently in the press (Co-op Printing, P.O. Box 50208, Lusaka, Zambia).

A deaf community in any country is a linguistic community with special linguistic needs including lexicographic needs which the country must endeavour to satisfy since all citizens have the same linguistic rights. The project was launched as a result of the realization that the linguistic rights of the Zambian deaf people, which include the development of a national sign language (since the Zambian deaf cannot use the national official language, English, in its spoken form), have been neglected or ignored.

Where there is a deaf community - through the establishment of a deaf school, deaf club, deaf centre, etc. - an elaborate manual system of communication emerges and eventually develops into a fully-fledged language comparable to articulated language in both scope and complexity (Chanda 1997: I, Serpell and Mbewe 1990: 281). Such a language is known as sign language (SL) in the linguistic literature.

Contrary to one widespread belief, SL language is not universal in the sense of there being only one SL worldwide. This belief is based on the fact that many SL signs are iconic, or pictorial, in that they somehow describe depictively what they mean or stand for. That SL is not universal in the sense defined above is evidenced by the existence of several SLs (American Sign Language, British Sign Language, Australian Sign Language, Chinese Sign Language, French Sign Language, Kenyan Sign Language, etc.) most of which are not mutually intelligible. At this juncture, three points must be made regarding iconicity in human language as a way of explaining why there exist several SLs which are not mutually intelligible. Firstly, many artefacts (e.g. houses) do not have the same set of features worldwide nor are all actions (e.g. building a house) performed in the same way worldwide. Consequently, given some artefact or action $X$ with some feature $F$ such that $X$ is $[+F]$ in culture $C 1$, but $[-F]$ in some other culture $C 2$, a deaf community belonging to $C 1$, but not to $C 2$, may "mimic" [+F] to refer to the artefact or action $X$, in which case a deaf person belonging to culture $C 2$ will not understand the sign. Secondly, even when some artefact or action $X$ has the same set of features in two different cultures, $C 1$ and $C 2$, deaf people belonging to $C 1$ and $C 2$ will not necessarily mimic the same feature from $X$. The latter point reminds us of the fact that articulated languages do not necessarily onomatopoeically depict the same sound in the same way. Lastly, within the same community a feature $F$ which is mimicked to refer to some artefact or action $X$.may be abandoned due to cultural change while the sign is retained so that the sign is iconic only diachronically.

It is also worth noting that LSs are not based on spoken languages, as is evidenced by the fact that, while American English and British English are mutually intelligible, American Sign Language (ASL) and British Sign Language (BSL) are not. 
Minimally an SL sign consists of four components, whose functions are the same as the function of distinctive features of phonemes in articulated language, namely:

(a) hand shape, i.e. the configuration of the active hand during the production of the sign,

(b) location, i.e. the place of articulation of the sign (e.g. the chin),

(c) movement, i.e. the movement of the hand(s) during the production of the sign, and

(d) orientation, i.e. the direction in which the palm(s) face(s) (e.g. downward, upward, left, right).

\section{Historical Background to the Zambian Sign Language}

The first school for deaf children in Zambia was opened in 1955 by the Dutch Reformed Church at their Magwero Mission in the Eastern Province. Since then several deaf schools, deaf school units, deaf clubs and deaf centres have been established countrywide and a national deaf association, the Zambian National Association of the Deaf (ZNAD), has been formed.

At the Magwero Mission School for the Deaf, the missionaries were essentially "oralists", that is to say, they were teaching the deaf somehow through speech and speechreading and writing, but the children soon developed an indigenous SL through, in the words of Serpell and Mbewe (1990: 283), crosscultural borrowing. Nowadays, the medium of instruction for the deaf in Zambia is to a large extent what is known as "total communication", i.e. a system whereby any means of communication (signing, gesturing, writing, pictures, etc.) is used, but American Sign Language (ASL) has undoubtedly become the most important medium of instruction and means of communication in deaf communities in Zambia. This is due to a number of teaching and promotional activities initiated by Mr Mackenzie Mbewe, a deaf person who holds a B.A.(Ed.) (University of Zambia, 1978) and a B.Phil. in Special Education (University of Birmingham, 1984). After studying at the lbadan School for the Deaf, Nigeria, for two years (1968-1970), he immediately started teaching and promoting ASL in Zambia. Mr Mbewe is currently the Executive Director of the ZNAD.

The increasing role played by SL in deaf education in Zambia and the realization that deaf people in the country use indigenous signs, most of which are similar, led to the decision to compile a Zambian Sign Language Dictionary, the core of which would be made of standardized indigenous signs while other signs would be borrowed from ASL. Such a dictionary would be the basis for the development of a Zambian Sign Language (ZAMSL), an idea which was the result of the rejection of "oralism" in favour of "manualism", because oralism 
limits access to knowledge, and impairs the relationship between deaf children and their parents while SL gives deaf children a normal development (Wallin 1993: 3).

\section{The Zambian Sign Language Dictionary}

\subsection{General}

As already stated, the Zambian Sign Language Dictionary is a product of the Zambian National Association for the Deaf (ZNAD). The lexicographical work was wholly funded by the Finnish Association of the Deaf (FAD).

\subsection{Objective}

The object of the Zambian Sign Language Dictionary Project was to compile an SL dictionary including:

(a) as many standardized signs as possible, and

(b) a sizeable ASL number of signs needed in deaf education in Zambia.

\subsection{Target Users}

The dictionary is primarily targeted at deaf schools and deaf school units but also at the clergy and government ministries such as the Ministry of Health, whose services are essential.

\subsection{Personnel}

To implement the project, a Sign Language Committee was set up comprising:

(a) two academic members of staff of the University of Zambia, including the writer,

(b) three hearing officials from the Ministry of Education, and

(c) six deaf members from the Zambian National Association of the Deaf (ZNAD).

The project was managed by the ZNAD and benefitted from services provided from time to time, but was aided throughout the duration of the project by SL experts from the Finnish Association of the Deaf (FAD). 


\subsection{Special Equipment}

Because of the nature of the language and work involved, the following pieces of equipment were used:

(a) a video camera,

(b) a still picture camera,

(c) a heavy-duty tripod,

(d) a colour television set, and

(e) drawing sets.

\subsection{Methodology}

\subsubsection{Data Collection}

All the signs were collected from deaf and hard-of-hearing people whose competence in written English was adequate for the purposes of the project. Most informants were at deaf schools, deaf school units, deaf clubs and deaf centres. The signs were collected during field work in several districts throughout the country with the use of a video camera and a still picture camera.

To collect signs, the field workers used a list of English words and sometimes phrases and the informants were asked to supply the equivalent indigenous signs. However, some informants were not always able to say whether the signs they gave, were indigenous or borrowed from ASL but this was not problematic since the researchers know ASL. The result was that three types of signs were collected:

(a) indigenous signs,

(b) ASL signs, and

(c) modified ASL signs.

Most signs were indigenous signs. It is important to note that, for the purposes of the project insofar as it is an aspect of language corpus planning, ASL signs and modified ASL signs were retained and regarded as ZAMSL signs borrowed from ASL.

\subsubsection{Lemmatization}

To decide which signs should be lemmatized, the signs collected during fieldwork had first to be ascertained at national conferences attended by the members of the Zambian Sign Language Committee as well as deaf and hard-of- 
hearing delegates from all over the country. The inclusion policy was as follows:

(a) where there was only one sign for a given English item retained, the sign had to be lemmatized, and

(b) where there was more than one sign retained for a given English item (which was generally the case for indigenous signs), it was agreed to lemmatize the sign which displayed the greatest geographical distribution except when two signs were thought to have practically equal geographical distribution, in which case both signs were lemmatized as synonyms.

\subsubsection{Processing}

The lemmas, i.e. those signs which had been selected for inclusion in the dictionary, were processed manually. The processing consisted in:

(a) drawing every sign,

(b) giving the English gloss,

(c) giving grammatical information about the English gloss,

(d) giving a verbal description (in English) of how the sign is to be produced, and, where necessary,

(e) giving cross-references.

\subsubsection{Evaluation and Editing}

All the processed signs had to be evaluated at national conferences which, as explained above, were attended by the members of the Zambian Sign Language Committee and delegates from all over the country. The final work, i.e. editing, was supervised by the writer.

\subsection{Type of Dictionary}

With regard to the number of languages involved, dictionaries are generally either monolingual or bilingual. However, there is no monolingual SL dictionary in which signs belonging to a given SL (e.g. ASL), are explained in signs belonging to the same SL. All published monolingual SL dictionaries involve an articulated language (e.g. English). In such dictionaries, the lemma is a lexeme or, sometimes, a phrase or a morpheme in an articulated language and the lemma is followed by a verbal description (in the same articulated language) of how the equivalent sign is to be produced. However, the verbal description is 
always followed by a photograph or, more often, a drawing of the sign, but such photographs or drawings are to be regarded only as "illustrations". Articles from a monolingual SL dictionary from Sternberg (1990: 34) are shown in Appendix A.

The Zambian Sign Language Dictionary is a bilingual dictionary with the following features:

(a) the lemma consists of a drawing representing a sign;

(b) the lemma is followed by:

(i) an English gloss,

(ii) the literal English gloss of a ZAMSL sentence containing the lemma (Exag, i.e. example of SL grammar),

(iii) the actual English gloss of the example in (ii) (Enlat, i.e. English language translation), and

(iv) a verbal description in English of how the sign is performed.

Among pieces of information which are found optionally, it is important to mention facial expression (FE). Examples of articles from the Zambian Sign Language Dictionary are shown in Appendix B.

\subsection{The Outer Access of the Zambian Sign Language Dictionary}

\subsubsection{General}

With reference to Hausmann and Wiegand (1989), Gouws (1996: 19) writes:

The dictionary user has to get to the information he needs, and the structure of the dictionary should help him to reach that information. This component of the dictionary is known as the access structure ... The outer access structure guides the user up to the lemma, whereas the inner access structure helps the user to reach the specific information category within an article. The access structure can also be described as the search path for the dictionary user.

For dictionaries in articulated language, the outer access structure is generally the alphabetical ordering of the lemmas. Likewise, in the type of monolingual SL dictionaries described in the previous section, the outer access structure is the alphabetical ordering of the lemmas.

The Zambian Sign Language Dictionary has been designed with two search systems, namely:

(a) the sign-word search system, which enables the user to identify the English equivalent(s) of a sign, and 
(b) the word-sign search system, which enables the user to locate the sign for a given English item.

\subsubsection{The Sign-Word Search System (SWSS)}

As explained above, the sign-word search system enables the dictionary user to identify the English equivalent of the sign he/she has seen. The SWSS is based on handshapes and locations (see 1.2) in that lemmas (signs) are arranged according to:

(a) the hand formation (handshape) at the beginning of the production of the sign, and

(b) location, i.e. on/near which part of the body the sign is made.

The first classification is by handshapes. Signs with the same initial handshape are classified in the same section, an arrangement which is reminiscent of alphabetical ordering. In the Zambian Sign Language Dictionary handshapes are ranked according to the number of lemmas (signs) they include and are arranged in such a way that a more frequently used handshape comes before a less frequently used one. In Appendix $C$ which shows the handshapes used in the Zambian Sign Language Dictionary S, E, A, etc., refer to the signs representing the ASL alphabet, which has been adopted in ZAMSL.

The second classification of the lemmas is by location. Within each section, containing all signs with the same initial handshape, signs are classified according to their locations, starting from above the head down to the main natural space as shown in Appendix D.

It is clear that with the above dual classification of signs, coupled with the fact that the table of contents gives the pages where the categories of handshapes and locations are found, any sign contained in the dictionary, can be easily located, provided that the user's observation of the sign is correct. The English gloss of the sign is given after the lemma.

\subsubsection{The Word-Sign Search System (WSSS)}

Let us suppose that a dictionary user wants to know the sign for "boy". The first thing to do is to locate "boy" in the English alphabetical index at the end of the dictionary. In this index, every item is followed by at least two numbers, the first of which is always the page number of the lemma and the other(s) is/are the number(s) of the lemma(s) (lemmas are numbered). Therefore, after locating "boy" in the index, the user will go to the indicated page number where he/ she will see the sign with the number indicated after the page number in the index. 


\section{Conclusion}

As it displays all the essential design features of human language (duality of structure, creativity, discreteness, spatial and temporal displacement, etc.), sign language as used by deaf communities is a real human language. Human language need not involve speech.

Sign language being a fully-fledged language and deaf people being a minority in any country, a deaf community is a minority linguistic community. However, by virtue of the nature of its language, which is its first language (L1), a deaf community has special linguistic needs which are difficult to meet but must be met somehow in order for the deaf and hard-of-hearing to be able to enjoy their rights as citizens and participate in national development.

In Zambia, like in most other countries in the Third World, deaf people have been neglected since their natural language, or first language (L1), that is to say, sign language, has been ignored. The Zambian Sign Language Dictionary Project was planned to partly remedy this serious deficit.

The study of sign language can greatly contribute to linguistic theory (Fischer 1979: 51-64) and sign language lexicography can contribute to the metalexicographical debate. Perhaps the most important lesson to be drawn from the Zambian Sign Language Dictionary Project is that in lexicography the methodology as well as the human and other resources to be used depend on the language involved.

\section{References}

Chanda, V.M. (Ed.). In the press. Zambian Sign Language Dictionary. Lusaka: Co-op Printing.

Fischer, Susan D. 1979. Twixt the Hand and the Lip: The Application of Linguistic Theory to Non-oral Languages. Application of Linguistic Theory in the Human Sciences: 45-75. East Lansing: Michigan State University, Department of Linguistics.

Gouws, R.H. 1996. Bilingual Dictionaries and Communicative Equivalence in a Multilingual Society. Lexikos 6: 14-31.

Hausmann, F.J. and H.E. Wiegand. 1989. Component Parts and Structures of Monolingual Dictionaries. Hausmann, F.J. et al. (Eds.). 1989-1991. Wörterbücher: Ein internationales Handbuch zur Lexikographie / Dictionaries: An International Encyclopedia of Lexicography / Dictionnaires: Encyclopédie internationale de lexicographie: 328-360. Berlin: Walter de Gruyter.

Serpell, R. and M. Mbewe. 1990. Dialectal Flexibility in Sign Language in Africa. Lucas, Ceil (Ed.). 1990. Sign Language Research: Theoretical Issues: 273-287. Washington, D.C.: Gallaudet University Press.

Stemberg, M.L.A. 1990. American Sign Language Concise Dictionary. New York: Harper and Row.

Wallin, L. 1993. Deaf People and Bilingualism. A paper presented at the International Conference on Bilingualism in Deaf Education, Stockholm, Sweden, August 16-20, 1993. 


\section{Appendix A: Examples of ASL Signs (Stemberg 1990)}

ereglasses ( $(T$ glàs 3 ), it $p$ l. (The shape) The thumb and index finger of the right hand, placed flat against the right temple, move bnck toward the right ear, tracing the line formed by the eyeglass frame. See also Glasses.
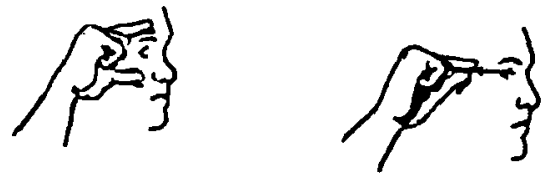

HEAD (hed), $n$ (The head is indicated.) The tips of the fingers of the right right-angle hand are placed at the right temple, and then move down in an are to the right jaw.

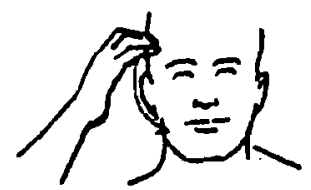


Appendix B: Examples of ZAMSL Signs

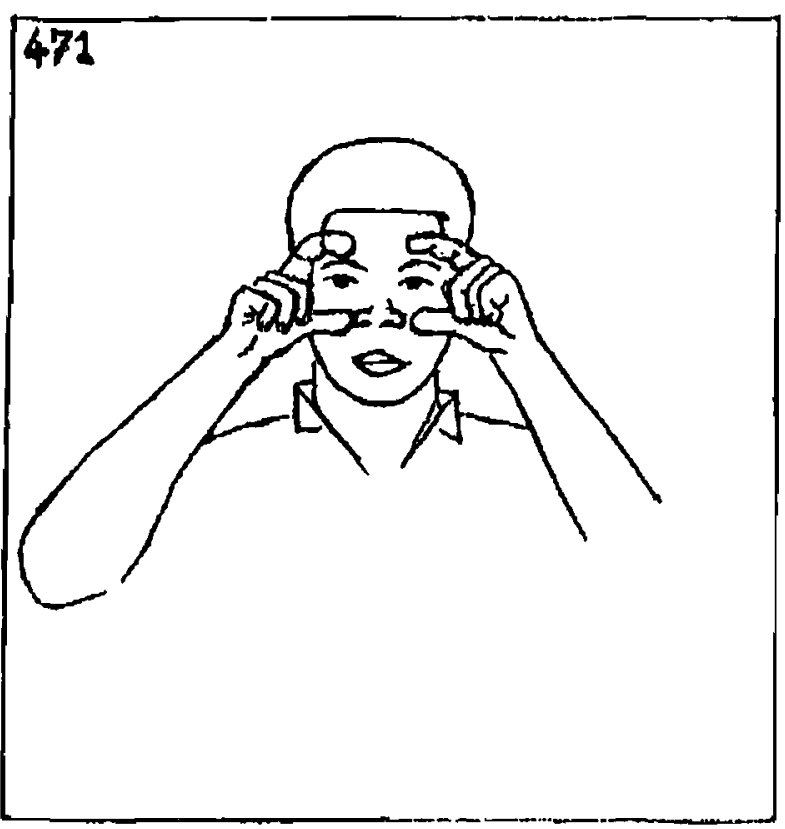

EYEGLASSES (n pl) SPECTACLES (n pl)

Usage:

Exag: Problems cye/ eyeglasses/expensive.

Enlat: Specucles for sight problems arc expensive.

Arliculation: Double-hand performance. With both hands in the 'bent L' hnnd position, palms facing each ollier, place them slightly to the front of each eye so that each eye is in belween the thumb and index finger. This indicates the shape of the lenses. 


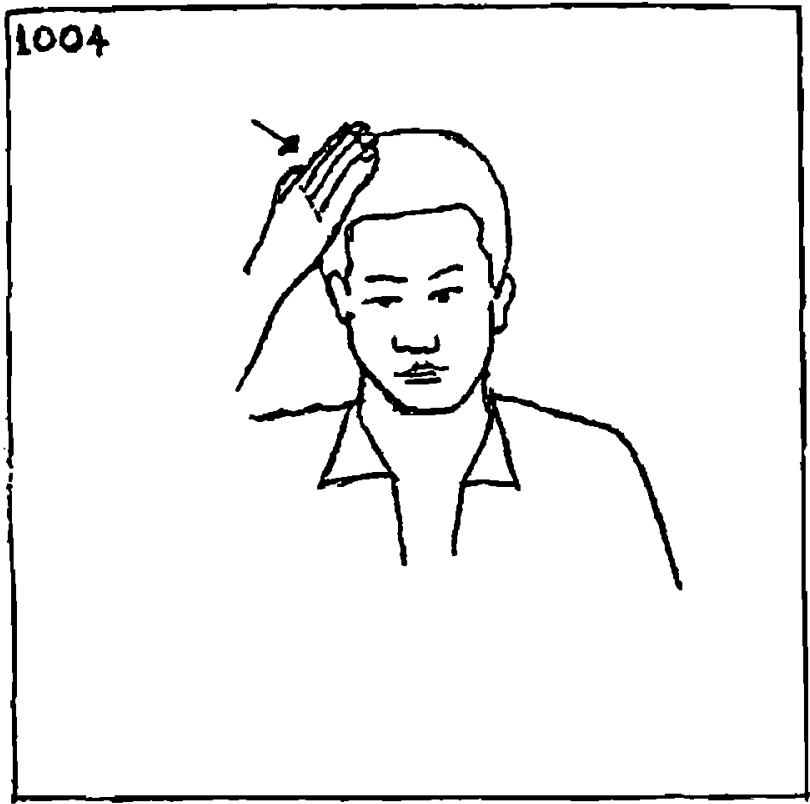

$\operatorname{HEAD}(n)$

Usage:

Exag: Butchery/me go/pig head/bury.

Enlat: I am gning to the butchery to buy the head of a pig.

Articulation: One-hand performance. Just touch the right temple using the palm of the dominant flat hand. ( Tapping can be done once or repeatedly "twice"). 
Appendix C: Ordering of Handshapes in the Zambian Sign Language Dictionary

Ilandshape Nane




Handshape Name


Appendix D: Body Locations in Sign Verbal Description

Right hand side

Location $\Lambda$ (Abovo the liead)

\section{Loft bands sido}

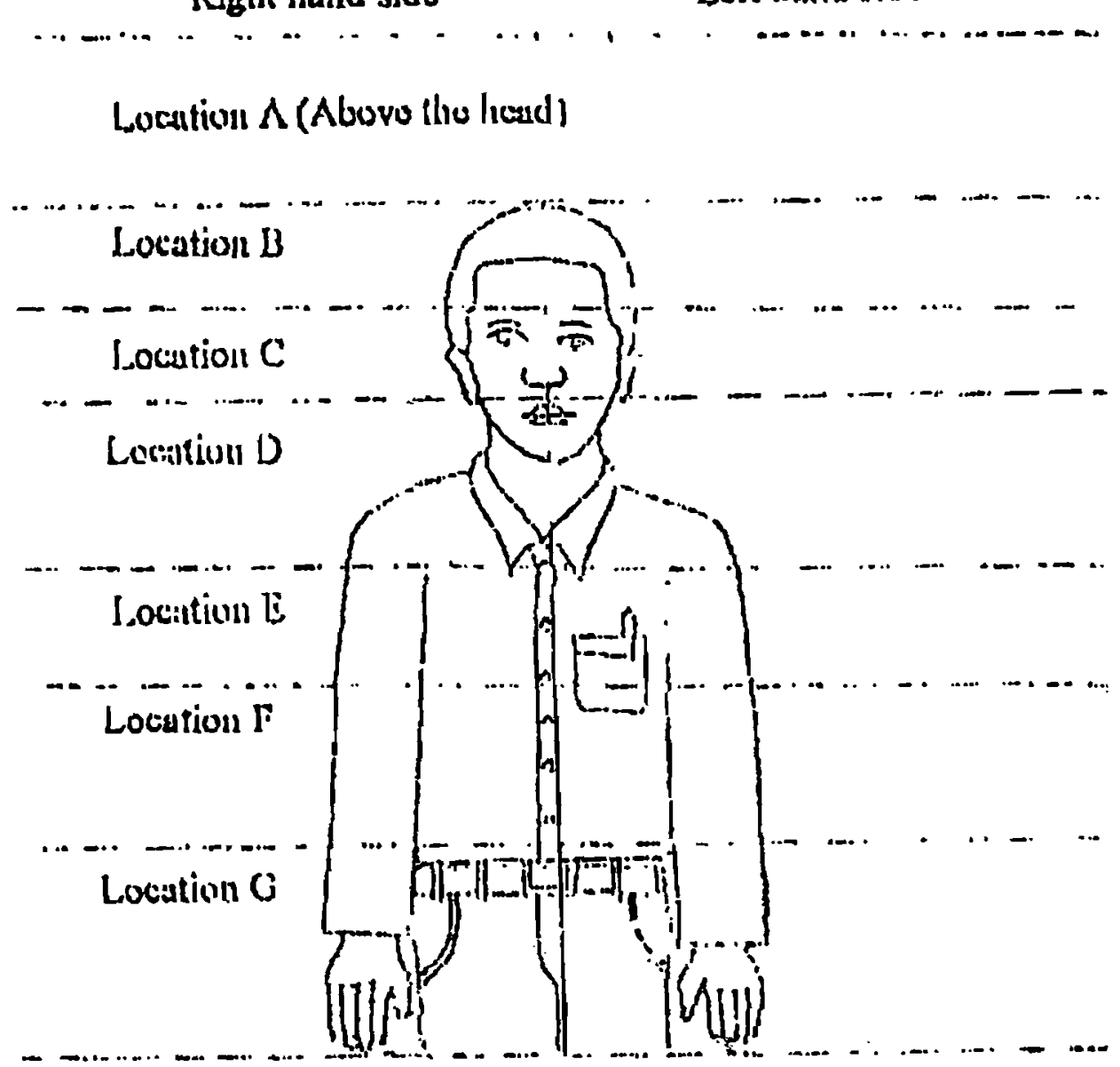

